\title{
Sur l'olivier
}

Préface à une œuvre picturale

\section{Mohammed Khadda}

\section{(2) OpenEdition}

1 Journals

Édition électronique

URL : http://journals.openedition.org/coma/597

DOI : $10.4000 /$ coma.597

ISSN : 2275-1742

Éditeur

Institut des textes \& manuscrits modernes (ITEM)

Référence électronique

Mohammed Khadda, «Sur l'olivier », Continents manuscrits [En ligne], 5 | 2015, mis en ligne le 15 octobre 2015, consulté le 19 avril 2019. URL : http://journals.openedition.org/coma/597 ; DOI : 10.4000/coma.597

Ce document a été généré automatiquement le 19 avril 2019

\section{(c) $(9)$}

Continents manuscrits - Génétique des textes littéraires - Afrique, Caraîbe, dispora est mis à disposition selon les termes de la licence Creative Commons Attribution - Pas d'Utilisation Commerciale - Pas de Modification 4.0 International. 


\title{
Sur l'olivier
}

\author{
Préface à une œuvre picturale
}

\author{
Mohammed Khadda
}

\begin{abstract}
$* * *$
Mohammed Khadda (Mostaganem, le 14 mars 1930 - Alger, le 4 mai 1991). Autodidacte, "peintre du Signe », sculpteur, graveur et théoricien de l'art. Employé, dès 1944, dans l'imprimerie de "L'Aïn Sefra » où il réalisait, entre autres, des maquettes. En 1947, il s'inscrit à un cours de dessin par correspondance et réalise ses premières aquarelles. Ainsi commence la grande aventure de l'expression plastique qui mène Mohammed Khadda de Mostaganem à Alger (où, au Musée des Beaux Arts, il regarde, entre autres, les toiles de Delacroix, Fromentin, Dinet et les sculptures de Rodin et de Bourdelle), ensuite à Paris (1953). Dans la capitale des arts, M. Khadda fait la connaissance de Kateb Yacine et milite pour la liberté de l'Algérie au parti communiste. Son développement artistique se poursuit : il visite les musées, dessine à l'Académie de la Grande Chaumière, participe à quelques expositions collectives.

Depuis 1954, il abandonne totalement la peinture figurative, qui, selon lui, ne correspond pas à la sensibilité algérienne. Il s'intéresse aux signes de la graphie arabe; sa toile Alphabet libre datant de cette époque donne la naissance à ce que Jean Sénac appellera «L'École du Signe ».

L'année 1961 est une année importante: M. Khadda réalise sa première exposition personnelle à Paris. Deux ans plus tard, il retourne en Algérie libre où il continue ses recherches sur les thèmes de l'olivier (à partir de 1967) et de la trace de la lettre (les années 1980). Il exécute aussi des gravures et des toiles, illustre les recueils de poèmes (Jean Sénac, Rachid Boudjedra, Bachir Hadj Ali), réalise les peintures murales et publie, en 1971, Éléments pour un art nouveau (histoire de l'art en Algérie) et, en 1983, Feuillets épars liés (ses préfaces et ses articles).

Oeuvres principales : Alphabet libre, la série des oliviers (p. ex. Olivier ronce, Olivier astre), Sahel sous le vent, Calligraphie des algues, ainsi que de nombreuses aquarelles (Aurore
\end{abstract}


d'automne, Cailloux transparents), gravures (Soliloque, Chardon) et sculptures (p. ex. Monument aux Martyrs à M'Sila).

Le carton d'invitation que nous présentons ici provient des archives de Mohammed Khadda. Il date de l'époque de sa fascination pour l'olivier (1967-1980), arbre-emblème de la Méditerranée, arbre appelé par le peintre "genèse ${ }^{1}$ ". L'exposition à l'occasion de laquelle le carton avait été préparé eut lieu à Alger, à l'U.N.D.A.P., du 16 au 31 janvier 1971. Le carton, comme le dit Mme N. Khadda, veuve du peintre : "est d'une grande sobriété [...] mais [il] est bien présenté sur papier coquille d'œuf et encre marron ${ }^{2}$.» La page 3, vierge, n'a pas été reproduite.

Fig. 1 Carton d'invitation p. 1/4

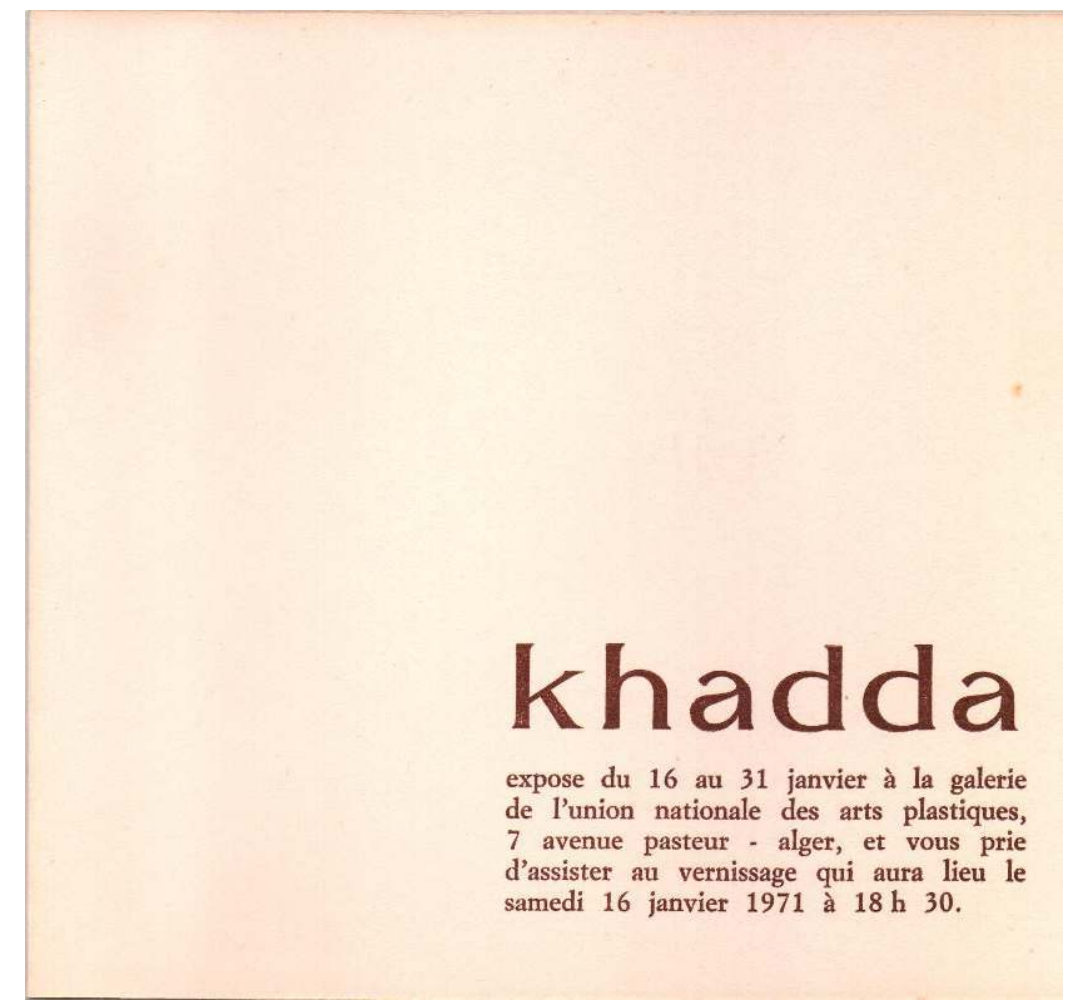

Reproduction avec l'aimable autorisation de Mme Naget Khadda, ayant droit de M. Khadda 
Fig. 2 Carton d'invitation p. 2/4

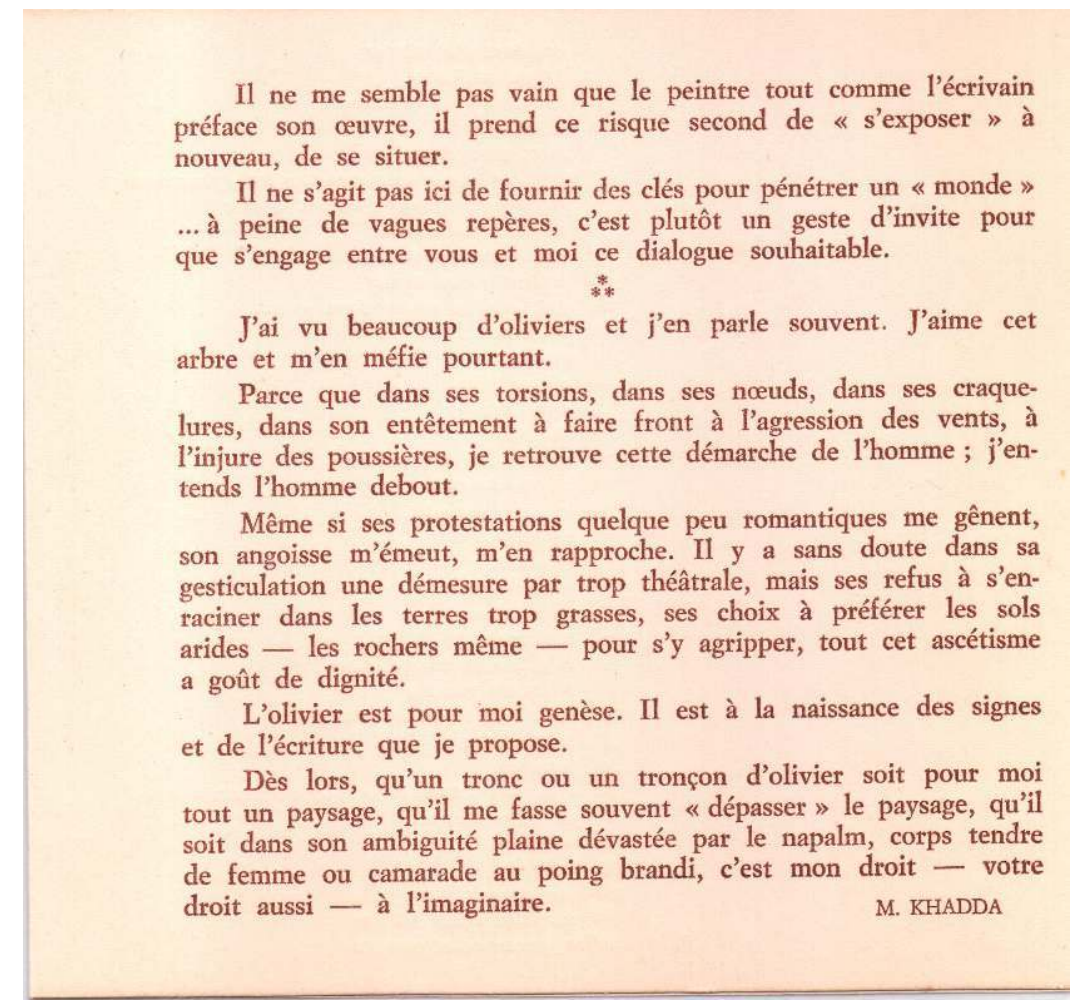

Reproduction avec l'aimable autorisation de Mme Naget Khadda, ayant droit de M. Khadda

Fig. 2 Carton d'invitation p. 4/4

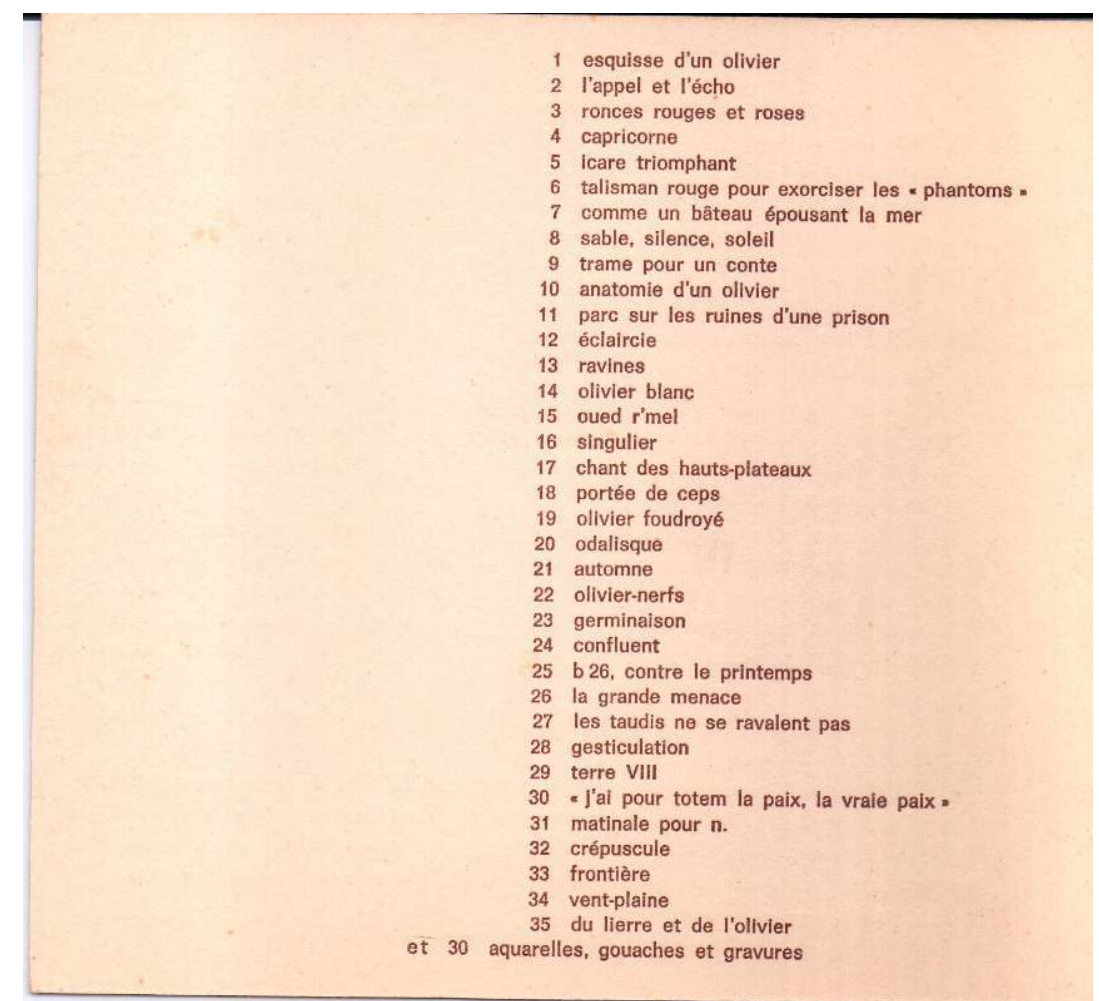

Reproduction avec l'aimable autorisation de Mme Naget Khadda, ayant droit de M. Khadda 


\section{NOTES}

1. Cf. le texte de M. Khadda ci-dessous.

2. Extrait d'un courriel à H. Sanson (le 10 octobre 2015). 